\title{
Molecular Imaging of Alzheimer Disease Pathology
}

K. Kantarci

\begin{abstract}
Development of molecular imaging agents for fibrillar $\beta$-amyloid positron-emission tomography during the past decade has brought molecular imaging of Alzheimer disease pathology into the spotlight. Large cohort studies with longitudinal follow-up in cognitively normal individuals and patients with mild cognitive impairment and Alzheimer disease indicate that $\beta$-amyloid deposition can be detected many years before the onset of symptoms with molecular imaging, and its progression can be followed longitudinally. The utility of $\beta$-amyloid PET in the differential diagnosis of Alzheimer disease is greatest when there is no pathologic overlap between 2 dementia syndromes, such as in frontotemporal lobar degeneration and Alzheimer disease. However $\beta$-amyloid PET alone may be insufficient in distinguishing dementia syndromes that commonly have overlapping $\beta$-amyloid pathology, such as dementia with Lewy bodies and vascular dementia, which represent the 2 most common dementia pathologies after Alzheimer disease. The role of molecular imaging in Alzheimer disease clinical trials is growing rapidly, especially in an era when preventive interventions are designed to eradicate the pathology targeted by molecular imaging agents.
\end{abstract}

ABBREVIATIONS: $\mathrm{A} \beta=\beta$-amyloid; $\mathrm{AD}=$ Alzheimer disease; $\mathrm{DLB}=$ dementia with Lewy bodies; $\mathrm{MCI}=$ mild cognitive impairment; $\mathrm{NIA}-\mathrm{AA}=\mathrm{National}$ Institutes of Aging and the Alzheimer's Association; $\mathrm{PiB}=$ Pittsburgh compound-B

$\mathbf{T}$ he pathologic hallmarks of Alzheimer disease $(\mathrm{AD})$ are neurofibrillary tangles of hyperphosphorylated $\tau$ and extracellular plaques of $\beta$-amyloid ( $\mathrm{A} \beta$ ) proteins, which involve the brain many years before the emergence of symptoms. Molecular imaging with agents that bind to $\mathrm{A} \beta$ and $\tau$ proteins may detect the presence and progression of Alzheimer disease pathology during the preclinical stage when the disease course may be altered by early intervention. Imaging of the $A \beta$ pathology with PET has been used in clinical research settings for almost a decade and was recently approved by the US Food and Drug Administration for clinical use. Imaging of $\tau$ pathology with PET has been investigated less; however, its impact on understanding the pathophysiology of $\mathrm{AD}$ and on treatment planning would be significant. Imaging of both $\mathrm{A} \beta$ and $\tau$ will likely contribute independently to early diagnosis, differential diagnosis, and the tracking of disease

Received August 23, 2013; accepted after revision November 9. From the Department of Radiology, Mayo Clinic, Rochester, Minnesota. Dr Kantarci's research program is funded by National Institutes of Health grants (R01AG040042; R21 NS066147; P50 AG16574/Project1; P50 AG44170/Project 2).

Please address correspondence to Kejal Kantarci, MD, Department of Radiology, Mayo Clinic, 200 First St SW, Rochester, MN 55905; e-mail: kantarci.kejal@ mayo.edu

- Indicates open access to non-subscribers at www.ajnr.org

http://dx.doi.org/10.3174/ajnr.A3847 progression during the preclinical, prodromal, and clinical stages of $\mathrm{AD}$.

\section{Detecting Preclinical and Prodromal AD Pathology with Molecular Imaging}

During the past decade, discovery of $A \beta$ imaging with Pittsburgh compound- $\mathrm{B}(\mathrm{PiB})^{1}$ PET provided a window into the pathophysiology of $\mathrm{AD}$ in living individuals. Although postmortem studies have long suggested a high prevalence of $\mathrm{A} \beta$ pathology with moderate-to-frequent plaques reaching $47 \%$ in cognitively normal older adults, imaging of $\mathrm{A} \beta$ pathology with PET provided an in vivo confirmation of this observation. The prevalence of $\mathrm{PiB}$ positivity ranges from $20 \%$ to $34 \%$ in independent cohorts of cognitively normal individuals. ${ }^{2-6}$ The variability is likely associated with the ascertainment of participants and the cutoff used for PiB positivity as well as the median age of the cohorts. For example, in a population-based study of cognitively normal older adults that included individuals with neurologic, psychiatric, or systemic illnesses, a representative sample of the population, the prevalence of $\mathrm{PiB}$ positivity was $31 \%$ with a global cortical $\mathrm{PiB}$ uptake cutoff of $>1.5$, but the prevalence increased to $44 \%$ with a cutoff of $>1.4,{ }^{7}$ which is on par with the postmortem studies in community-based cohorts of cognitively normal elderly. ${ }^{8}$

Although $\mathrm{A} \beta$ pathology is common in cognitively normal individuals, the harmful effects of $A \beta$ pathology on cognitive func- 

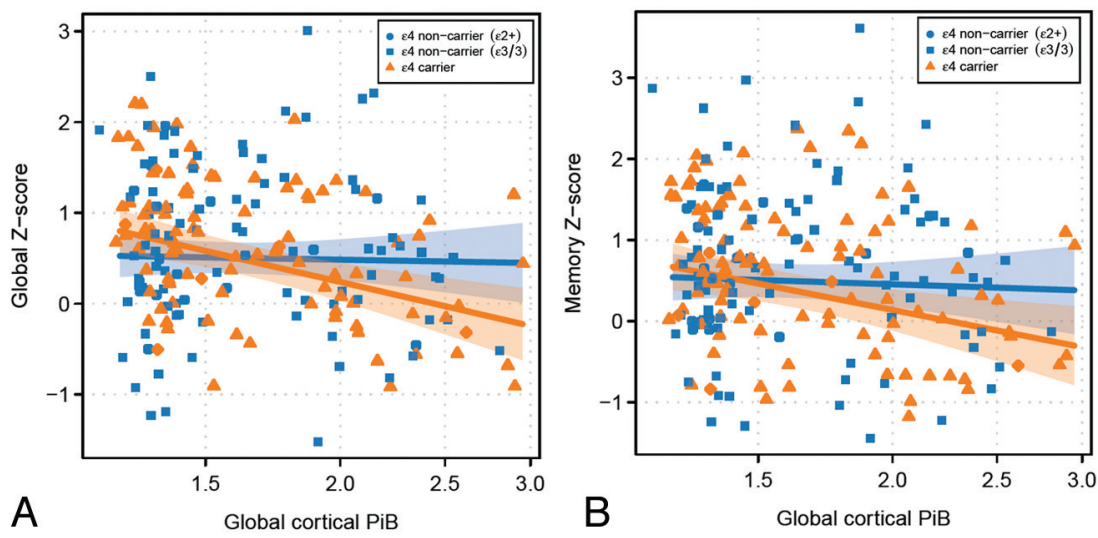

FIG 1. Associations between cortical PiB retention and standardized memory and global cognitive domain scores according to $A P O E \varepsilon 4$ status. Higher $A \beta$ load is associated with greater global cognitive impairment (partial $\left.r_{\mathrm{s}}=-0.18 ; P<.01\right)(A)$ and memory impairment (partial $r_{\mathrm{s}}=$ $-0.14 ; P<.01)(B)$. However global cognitive function in APOE $\varepsilon 4$ carriers is influenced more by the $A \beta$ load compared with $A P O E \varepsilon 4$ noncarriers matched by age, sex, education, and $A \beta$ load (sequential ANOVA interaction; $P=.01$ ), suggesting that $A P O E$ isoforms modulate the harmful effects of $A \beta$ on cognitive function $(A)$. A similar trend is seen with memory function (sequential ANOVA interaction; $P=.08$ ). Reprinted with permission from Kantarci K, Lowe $\mathrm{V}$, Przybelski SA, et al. APOE modifies the association between Abeta load and cognition in cognitively normal older adults. Neurology 2012;78:232-40.5

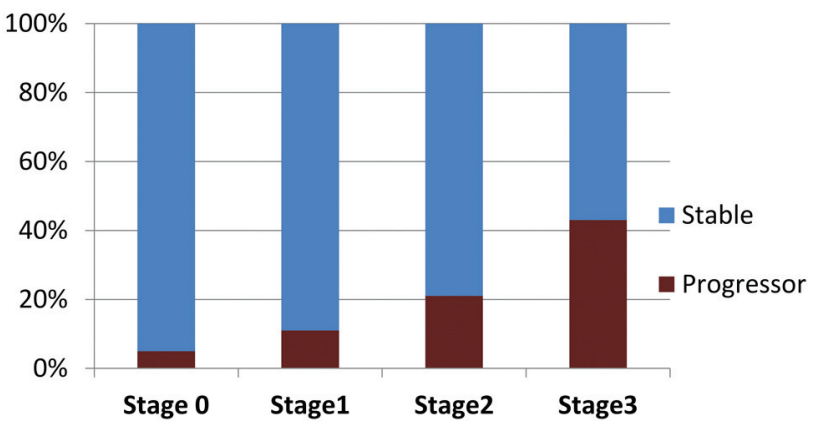

FIG 2. Preclinical staging of Alzheimer disease and short-term progression rates. If one used the preclinical staging criteria, at fixed cut-points corresponding to $90 \%$ sensitivity for diagnosing $A D$ and the 10th percentile of cognitive scores of cognitively healthy individuals, stage 0 corresponds to a low A $\beta$ load on PET and the absence of imaging markers of neuronal injury (ie, normal hippocampal volumes on MR imaging and/or the absence of an AD-like pattern of hypometabolism on PET); stage 1 corresponds to a high $\mathrm{A} \beta$ load on PET and the absence of imaging markers of neuronal injury; stage 2 corresponds to a high $A \beta$ load on PET and the presence of imaging markers of neuronal injury; and stage 3 corresponds to a low $A \beta$ load on PET, the presence of imaging markers of neuronal injury, and subtle cognitive impairment. The percentage of patients who progressed to mild cognitive impairment during a median follow-up of 15 months is demonstrated. The diagnosis of $\mathrm{MCl}$ was made according to the Petersen criteria, ${ }^{90}$ blinded to the imaging biomarker data used for staging.

tion are modest. ${ }^{5,9-12}$ The risk of cognitive decline further increases with the $\mathrm{A} \beta$ load. ${ }^{6,13,14}$ The high $\mathrm{A} \beta$ load on PET appears to have subtle effects on memory, attention/executive function, and visual-spatial processing. ${ }^{5,6,10,13-18}$ The relationship between $\mathrm{A} \beta$ load and cognitive domain functions does not appear to follow a specific functional-anatomic pattern but is localized to the frontal, lateral temporal, and parietal lobes; posterior cingulate; and precuneus cortex, independent of the cognitive domains that are affected. ${ }^{5}$ Therefore the effects of $\mathrm{A} \beta$ detected on PET appear to be global, and the APOE $\varepsilon 4$ status further modifies the association between $\mathrm{A} \beta$ load and cognition. ${ }^{5,19}$ Although cognitively normal carriers of the APOE $\varepsilon 4$ have higher $A \beta$ loads on PET compared with noncarriers, ${ }^{3,5,20}$ when matched on $\mathrm{A} \beta$ load, $A P O E \varepsilon 4$ carriers tend to perform worse on cognitive tests compared with noncarriers (Fig 1). ${ }^{5}$ Thus, APOE $\varepsilon 4$ not only increases the risk for $\mathrm{A} \beta$ deposition but also influences $\mathrm{AD}$ pathology by modulating the harmful effects of $A \beta$ on cognitive function through other potentially synergistic mechanisms, such as enhancing hyperphosphorylation of the $\tau$ protein $^{21}$ and reducing choline acetyltransferase activity. ${ }^{22}$

In 2011, the clinical diagnostic criteria for $\mathrm{AD}$ were revised under the auspices of the National Institutes of Aging and the Alzheimer's Association (NIA-AA). ${ }^{23}$ These new guidelines included imaging markers in the diagnostic criteria for $\mathrm{AD}$ and proposed research criteria that included imaging evidence of $\mathrm{AD}$ for the diagnosis of preclinical $\mathrm{AD}{ }^{24}$ The new criteria require evidence of $\mathrm{A} \beta$ pathology of $\mathrm{AD}$ for the diagnosis of preclinical $\mathrm{AD}$ either through molecular imaging or CSF biomarkers. Any imaging or biomarker evidence of $\mathrm{AD}$-related neurodegeneration measured with an $\mathrm{AD}$ pattern of atrophy on MR imaging or an $\mathrm{AD}$ pattern of hypometabolism on $\left[{ }^{18} \mathrm{~F}\right]$ fluorodeoxyglucose PET and the presence of subtle cognitive difficulties in addition to the $\mathrm{A} \beta$ pathology increase the stage of preclinical AD from 1 to 3 .

The preclinical AD research criteria was operationalized in a population-based sample of cognitively normal older adults from the Mayo Clinic Study of Aging. ${ }^{25}$ At fixed cut-points corresponding to $90 \%$ sensitivity for diagnosing $\mathrm{AD}$ and the 10 th percentile of cognitive scores of cognitively normal individuals, $43 \%$ of the sample was classified as stage $0 ; 16 \%$, stage 1 (A $\beta$ PETpositive); $12 \%$, stage 2 (A $\beta$ PET-positive and neurodegenerationpositive on MR imaging or FDG-PET); and $3 \%$, stage 3 (A $\beta$ PET-positive and neurodegeneration-positive on MR imaging or FDG-PET and subtle cognitive difficulties). ${ }^{26}$ Furthermore, the proportion of subjects who progressed to mild cognitive impairment (MCI) or dementia increased with advancing stage (Fig 2). ${ }^{27}$ However, $23 \%$ of the population did not fit the preclinical AD stages because they had normal A $\beta$ PET imaging findings but abnormal neurodegeneration biomarker study findings, which we classified as suspected non-AD pathophysiology. The suspected non-AD pathophysiology group is of particular interest because the individuals progress to $\mathrm{MCI}$ in the short term (10\% in 15 months), albeit at a rate similar to that of subjects with stage 1 preclinical AD (11\% in 15 months). The pathologic basis of positive neurodegeneration biomarker findings in the absence of $\mathrm{A} \beta$ pathology in this cognitively normal group is under investigation. ${ }^{28}$

According to the new guidelines by the NIA-AA, the prodromal stage of $\mathrm{AD}$ is characterized by mild cognitive impairment, and research criteria further classify patients with MCI as having $\mathrm{MCI}$ due to $\mathrm{AD}$ on the basis of biomarker evidence of $\mathrm{AD}$ pathophysiology. A recent study from the Mayo Clinic Study of Aging 

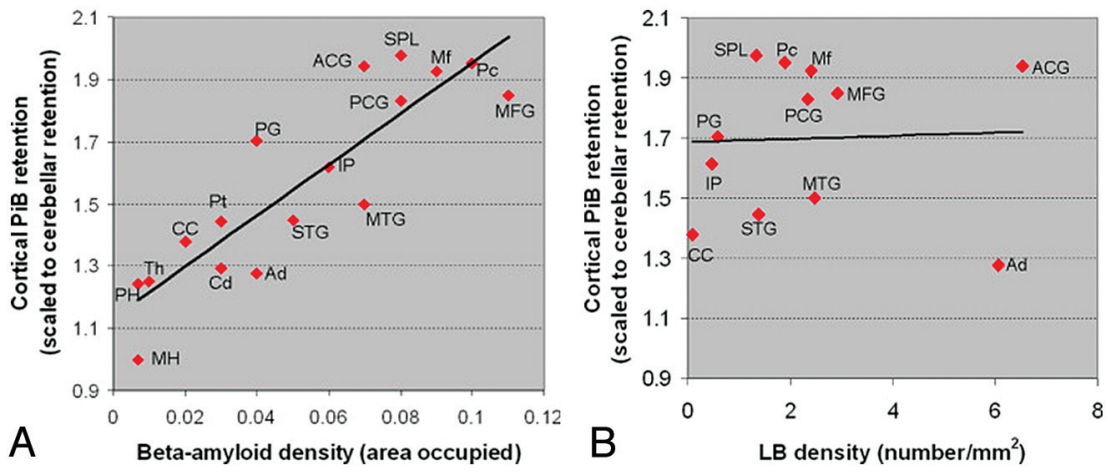

FIG 3. Correlations of cortical PiB retention and $A \beta(A)$ and Lewy body $(B)$ densities in individual brain regions of a case with dementia with Lewy bodies. There was a strong correlation between PiB retention and $A \beta$ attenuation in the 17 ROls that were analyzed on pathologic examination by using the Spearman rank-order correlation $(r=0.899 ; P<.0001)$. There was no correlation between Lewy body attenuation and $\mathrm{PiB}$ retention $(r=0.13 ; \mathrm{P}=.66)$. $\mathrm{MH}$ indicates middle hippocampus; $\mathrm{PH}$, posterior hippocampus; Th, thalamus; Cd, caudate; Ad, amygdala; CC, calcarine cortex; Pt, putamen; STG, superior temporal gyrus; MTG, middle temporal gyrus; IP, inferior parietal; PG, precentral gyrus; PCG, posterior cingulate gyrus; MFG, middle frontal gyrus; Mf, midfrontal; ACG, anterior cingulate gyrus; Pc, precuneus; SPL, superior parietal lobule. Reprinted from Neurobiology of Aging, Vol. 33(5), Kantarci K, Yang C, Schneider JA, et al. Antemortem amyloid imaging and beta-amyloid pathology in a case with dementia with Lewy bodies. p. 878-885, 2012, with permission from Elsevier. ${ }^{47}$

and Alzheimer Disease Neuroimaging Initiative demonstrated that the NIA-AA criteria apply to most subjects with MCI in both the community and clinical trial settings; however, a sizeable proportion of subjects had conflicting biomarkers, which need to be investigated. ${ }^{29}$ In this population, neurodegeneration on MRI increased the rate of progression to dementia in patients with MCI due to $\mathrm{AD}$ and appeared to be a key factor in predicting progression relative to $\mathrm{A} \beta$ deposition alone.

Molecular imaging studies with $\mathrm{A} \beta$-binding ligands in preclinical $\mathrm{AD}$ indicate that approximately one-third of the population of cognitively normal individuals and $71 \%$ of patients with $\mathrm{MCI}$ in the community have high cortical $\mathrm{A} \beta$ loads. In cognitively normal individuals, high levels of $\mathrm{A} \beta$ deposition are associated with subtle cognitive deficits, cognitive decline, and a higher risk of cognitive impairments in the future. However, these relationships appear to be modified by the genetic markers, ${ }^{5,30}$ lifestyle activities, ${ }^{31}$ or cognitive reserve. ${ }^{32}$

\section{Molecular Imaging for the Differential Diagnosis of $A D$}

The high sensitivity and specificity of $\mathrm{PiB}$ binding to fibrillar $\mathrm{A} \beta$ have been demonstrated in vitro, ${ }^{33}$ in mouse models, ${ }^{34}$ and in human tissue. ${ }^{35}$ The newer $\left[{ }^{18} \mathrm{~F}\right]$ agents for $\mathrm{A} \beta$ PET have undergone a similar validation process ${ }^{36-40}$ and appear to show properties similar to those of $\mathrm{PiB} .^{41-45}$ The specificity of $\mathrm{PiB}$ to fibrillar $\mathrm{A} \beta$ is preserved even in patients with protein deposits associated with other neurodegenerative dementias such as $\alpha$-synuclein in dementia with Lewy bodies (DLB) (Fig 3). ${ }^{46-49}$ However, there may be disagreements between the postmortem report and the PET findings because of the heterogeneity of $A \beta$ deposits. For example, PiB labels both neuritic and diffuse plaques, though labeling of diffuse/amorphous plaques is less prominent than that of compact/cored plaques. ${ }^{35,50}$ Patients with dementia with Lewy bodies or Parkinson disease dementia, who typically have high loads of diffuse plaques, may have positive A $\beta$ PET scan findings but would not be classified as having AD because of the absence of neuritic plaques and a low Braak neurofibrillary tangle stage. ${ }^{46,47}$ Another example is cerebral amyloid angiopathy. PiB binds to vascular amyloid in patients with cerebral amyloid angiopathy, but not all patients with cerebral amyloid angiopathy have parenchymal $\mathrm{A} \beta$ deposits for the diagnosis of $\mathrm{AD}$. Thus, while $\mathrm{PiB}$ is highly specific to $A \beta$, not all $A \beta$ deposits may be considered for the pathologic diagnosis of $\mathrm{AD} .^{35,50}$ Furthermore, there appears to be a threshold for detection in which it may not be possible to detect low levels of fibrillar $A \beta$ deposition. ${ }^{51}$ Nonetheless, the agreement between high A $\beta$ load on PET and a pathologic diagnosis of AD in the clinical setting is high and is demonstrated in antemortem imaging and postmortem confirmation studies and case series. ${ }^{52-54}$ The sensitivity and specificity of amyloid PET tracers to the different fibrillar $\mathrm{A} \beta$ deposits need further investigation.

One of the key applications of $\mathrm{A} \beta$ PET imaging in clinical practice is in the differential diagnosis of $A D$. The accuracy of $A \beta$ $\mathrm{PET}$ in distinguishing $\mathrm{AD}$ and frontotemporal lobar degeneration is quite high, ${ }^{55}$ with an overall classification accuracy of $97 \%$ in cases with histopathologic confirmation. ${ }^{56}$ On the other hand, the 2 most common dementia pathologies after AD are vascular disease and Lewy body pathologies, which commonly are present with additional $\mathrm{AD}$ pathology. In these cases, the presence of an intermediate-to-high $\mathrm{A} \beta$ load may be insufficient to determine the predominant pathology contributing to the dementia syndrome. In keeping with the postmortem data, $25 \%-35 \%$ of patients with vascular dementia ${ }^{57,58}$ and $60 \%-80 \%$ of patients with $\mathrm{DLB}^{46,54,59-62}$ have high $\mathrm{A} \beta$ loads on PET. Thus high levels of amyloid load may be insufficient in distinguishing these dementia syndromes from $\mathrm{AD}$, and a multitechnique imaging approach may be useful. We have shown that FDG-PET, A $\beta$ PET, and structural MR imaging are complementary in distinguishing patients with $A D$ and $\mathrm{DLB}^{54}$ and may be useful in predicting the presence of AD pathology in patients with DLB (Fig 4). ${ }^{63}$ Molecular imaging of the impaired nigrostriatal dopaminergic transmission in DLB with $2 \beta$-carbomethoxy-3 $\beta$-(4-iodophenyl)-N-(3-fluoropropyl) nortropane with SPECT ${ }^{64}$ or loss of monoaminergic terminal integrity with vesicular monoamine transporter type 2 radioligands may further detect the Lewy body-related pathologic features in cases with mixed dementia and may be complementary to $\mathrm{A} \beta$ PET. ${ }^{65}$

The added diagnostic value of $\mathrm{A} \beta$ PET imaging in the differential diagnosis of dementia across different clinical settings has become a topic of significant interest with the availability of $\left[{ }^{18} \mathrm{~F}\right]$ agents for $A \beta$ imaging. ${ }^{66-70}$ Although the added value of $A \beta$ PET to clinical decision-making has not been established, ${ }^{66-69}$ how $\mathrm{A} \beta$ load is measured on PET scans (ie, visual evaluation versus various quantitative techniques) appears to make a difference in the value of this diagnostic technique in the clinical setting. ${ }^{69}$ 

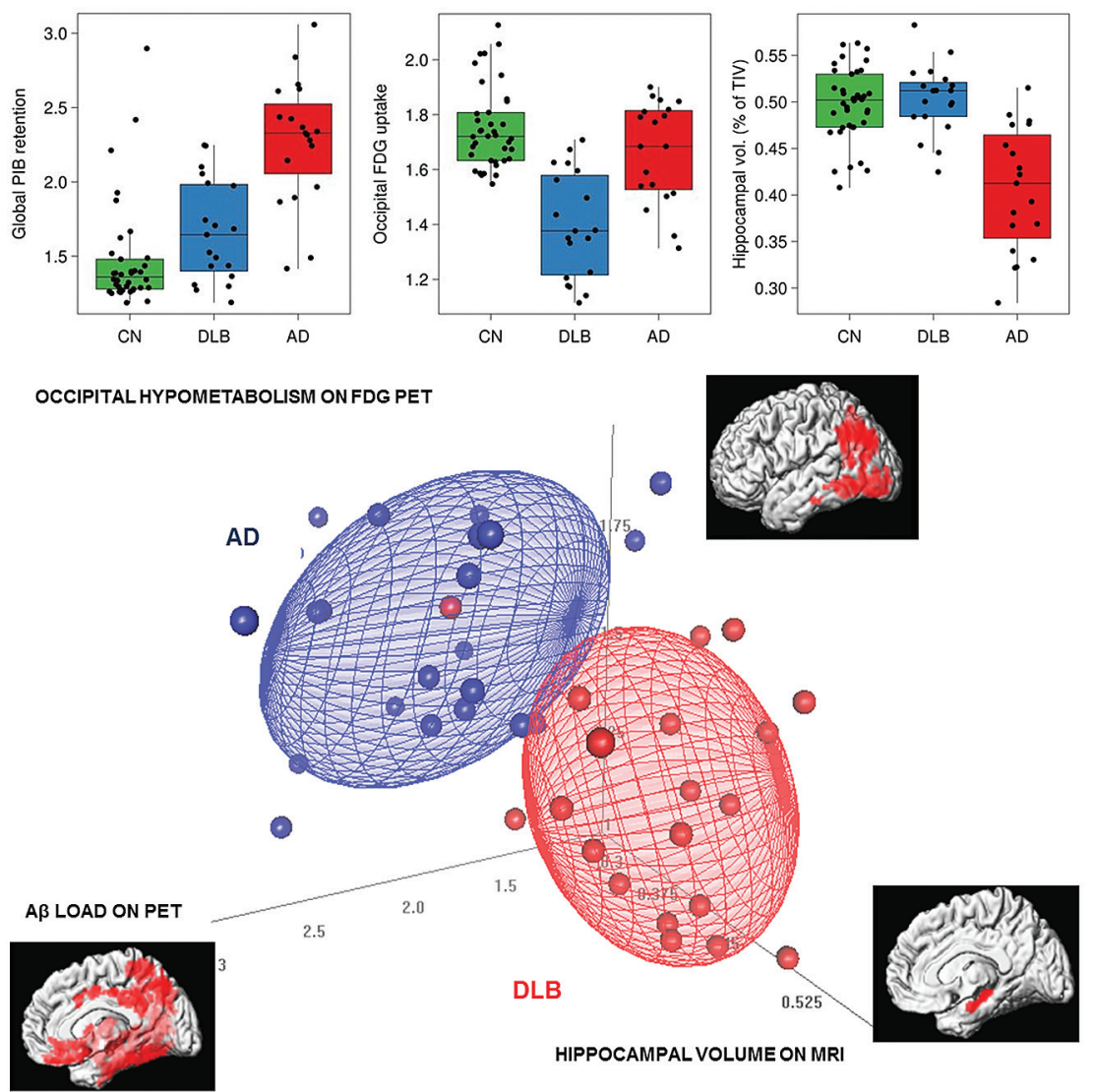

FIG 4. Multitechnique imaging markers in distinguishing Alzheimer disease and dementia with Lewy bodies. Regional FDG hypometabolism and PiB uptake on PET in patients with probable DLB $(n=21)$ are compared with those in control subjects ( $n=42)$; and gray matter atrophy in patients with $\operatorname{AD}(n=21)$ is compared with that in patients with DLB, displayed on surfacerendered brain images by using SPM (Wellcome Department of Imaging Neuroscience, London, UK) $(P<.05$; family-wise error corrected for multiple comparisons). Although occipital lobe hypometabolism, global cortical PiB retention, and hippocampal volumes (percentage of total intracranial volume) were overlapping among patients with probable DLB and AD as shown in box-plots in the top panel, a multitechnique imaging approach almost completely separated the patients with $\mathrm{DLB}$ and $\mathrm{AD}$. Logistic regression modeling demonstrated that each imaging technique independently contributed to distinguishing the patients with $A D$ and DLB with an area under the receiver operating characteristic curve of 0.98. Reprinted from Neurobiology of Aging, Vol. 33(9), Kantarci K, Lowe VJ, Boeve BF, et al. Multimodality imaging characteristics of dementia with Lewy bodies. p. 2091-2105, 2012, with permission from Elsevier. ${ }^{45}$

\section{Longitudinal Molecular Imaging for Tracking AD Pathology}

Longitudinal imaging of the $\mathrm{A} \beta$ load on PET provides evidence of the progression of $\mathrm{A} \beta$ deposition in the preclinical-to-clinical $\mathrm{AD}$ spectrum. The hypothetic model proposed by Jack et $\mathrm{al}^{71}$ indicates that $\mathrm{A} \beta$ deposition detected with molecular imaging and CSF biomarkers follows an accelerated course early in the disease process during the preclinical and MCI stages but slows down during the Alzheimer disease stage and reaches a plateau at very high levels. The findings of many longitudinal biomarker studies on $\mathrm{A} \beta$ deposition agree with this model. ${ }^{72-81}$ Cognitively normal individuals who progress to MCI and patients with MCI who progress to $\mathrm{AD}$ appear to have the highest rates of $\mathrm{A} \beta$ deposition, ${ }^{79}$ correlating with cognitive decline early in the disease course. ${ }^{76,77}$ Furthermore, a higher baseline $\mathrm{A} \beta \operatorname{load}^{78,80}$ and the presence of $A P O E \varepsilon 4^{79}$ are associated with higher rates of $\mathrm{A} \beta$ deposition. However, the association between higher baseline $\mathrm{A} \beta$ load measured with the standardized uptake value ratio and a targets for prevention.

\section{REFERENCES} 2004;55:306-19 higher rate of $\mathrm{A} \beta$ deposition appear to dissipate at very high levels (roughly 2.0 standardized uptake value ratio). After this threshold, the relationship becomes an inverted $\mathrm{U}$, gradually declining and reaching zero at the highest baseline $\mathrm{A} \beta$ load levels (2.7 standardized uptake value ratio). The time estimated to start with positive findings on a PiB scan (1.5 standardized uptake value ratio) to the point of plateau is approximately 15 years, corresponding to a large therapeutic window for clinical trials. ${ }^{73}$

\section{Molecular Imaging in Clinical Trials for $A D$}

In autosomal dominant $\mathrm{AD}$, the age of symptom onset can be predicted. It is estimated that increased $\mathrm{A} \beta$ deposition precedes clinical symptoms for approximately 15 years, providing a wide window for preventive therapies. ${ }^{82,83}$ The role of molecular imaging in clinical trials targeting the pathology captured with the molecular imaging agent can be 2-fold: 1) to determine who has the target pathology and enrichment of trials with this information; and 2) to determine whether a treatment is modifying the target pathology. Both of these applications of $\mathrm{A} \beta$ imaging are being used in current clinical trials of amyloid-modifying therapies for both treatment and prevention of $\mathrm{AD}{ }^{84,85}$ Findings from the bapineuzumab phase 2 double-blind placebocontrolled, ascending-dose study indicate that lowering of cortical fibrillar $A \beta$ with bapineuzumab can be detected with $\mathrm{PiB}$ PET. ${ }^{86}$ However, even though there were reductions in the $\mathrm{A} \beta$ load, the bapineuzumab trials were halted due to lack of improvement in clinical and functional outcomes in patients with AD dementia. Similarly, it is expected that imaging of the $\tau$ pathology of $\mathrm{AD}^{87,88}$ especially with agents specific to the $\tau$ pathology that are currently being developed and tested, ${ }^{89}$ will open avenues for development of new

Disclosures: Kejal Kantarci-RELATED: Grant: National Institutes of Health, ${ }^{*}$ UNRELATED: Board Membership: Jannsen, ${ }^{\star}$ Pfizer, ${ }^{*}$ Takeda, ${ }^{\star}$ Comments: data-monitoring board member, Grants/Grants Pending: National Institutes of Health, * Travel/ Accommodations/Meeting Expenses Unrelated to Activities Listed: Institute for Clinical and Economic Review.* *Money paid to the institution.

1. Klunk WE, Engler H, Nordberg A, et al. Imaging brain amyloid in Alzheimer's disease with Pittsburgh compound-B. Ann Neurol

2. Pike KE, Ellis KA, Villemagne VL, et al. Cognition and beta-amyloid in preclinical Alzheimer's disease: data from the AIBL study. $\mathrm{Neu}$ ropsychologia 2011;49:2384-90 
3. Morris JC, Roe CM, Xiong C, et al. APOE predicts amyloid-beta but not tau Alzheimer pathology in cognitively normal aging. Ann Neurol 2010;67:122-31

4. Aizenstein HJ, Nebes RD, Saxton JA, et al. Frequent amyloid deposition without significant cognitive impairment among the elderly. Arch Neurol 2008;65:1509-17

5. Kantarci K, Lowe V, Przybelski SA, et al. APOE modifies the association between Abeta load and cognition in cognitively normal older adults. Neurology 2012;78:232-40

6. Landau SM, Mintun MA, Joshi AD, et al. Amyloid deposition, hypometabolism, and longitudinal cognitive decline. Ann Neurol 2012;72:578-86

7. Mielke MM, Wiste HJ, Weigand SD, et al. Indicators of amyloid burden in a population-based study of cognitively normal elderly. Neurology 2012;79:1570-77

8. Sonnen JA, Larson EB, Crane PK, et al. Pathological correlates of dementia in a longitudinal, population-based sample of aging. Ann Neurol 2007;62:406-13

9. Pike KE, Savage G, Villemagne VL, et al. Beta-amyloid imaging and memory in non-demented individuals: evidence for preclinical Alzheimer's disease. Brain 2007;130:2837-44

10. Chételat G, Villemagne VL, Pike KE, et al. Relationship between memory performance and beta-amyloid deposition at different stages of Alzheimer's disease. Neurodegener Dis 2012;10:141-44

11. Fagan AM, Mintun MA, Shah AR, et al. Cerebrospinal fluid tau and ptau(181) increase with cortical amyloid deposition in cognitively normal individuals: implications for future clinical trials of Alzheimer's disease. EMBO Mol Med 2009;1:371-80

12. Mormino EC, Kluth JT, Madison CM, et al. Episodic memory loss is related to hippocampal-mediated beta-amyloid deposition in elderly subjects. Brain 2009;132:1310-23

13. Doraiswamy PM, Sperling RA, Coleman RE, et al. Amyloid-beta assessed by florbetapir F 18 PET and 18-month cognitive decline: a multicenter study. Neurology 2012;79:1636-44

14. Chételat G, Villemagne VL, Pike KE, et al. Independent contribution of temporal beta-amyloid deposition to memory decline in the predementia phase of Alzheimer's disease. Brain 2011;134:798-807

15. Rentz DM, Amariglio RE, Becker JA, et al. Face-name associative memory performance is related to amyloid burden in normal elderly. Neuropsychologia 2011;49:2776-83

16. Rodrigue KM, Kennedy KM, Devous MD Sr, et al. Beta-amyloid burden in healthy aging: regional distribution and cognitive consequences. Neurology 2012;78:387-95

17. Sperling RA, Johnson KA, Doraiswamy PM, et al. Amyloid deposition detected with florbetapir F 18 ((18)F-AV-45) is related to lower episodic memory performance in clinically normal older individuals. Neurobiol Aging 2013;34:822-31

18. Hedden T, Oh H, Younger AP, et al. Meta-analysis of amyloid-cognition relations in cognitively normal older adults. Neurology 2013; 80:1341-48

19. Lim YY, Ellis KA, Ames D, et al. Abeta amyloid, cognition, and APOE genotype in healthy older adults. Alzheimers Dement 2013;9:538 -45

20. Fleisher AS, Chen K, Liu X, et al. Apolipoprotein E epsilon4 and age effects on florbetapir positron emission tomography in healthy aging and Alzheimer disease. Neurobiol Aging 2013;34:1-12

21. Ledesma MD, Medina M, Avila J. The in vitro formation of recombinant tau polymers: effect of phosphorylation and glycation. Mol Chem Neuropathol 1996;27:249-58

22. Dubelaar EJ, Verwer RW, Hofman MA, et al. ApoE epsilon4 genotype is accompanied by lower metabolic activity in nucleus basalis of Meynert neurons in Alzheimer patients and controls as indicated by the size of the Golgi apparatus. J Neuropathol Exp Neurol 2004;63:159-69

23. Jack CR Jr, Albert MS, Knopman DS, et al. Introduction to the recommendations from the National Institute on Aging-Alzheimer's Association workgroups on diagnostic guidelines for Alzheimer's disease. Alzheimers Dement 2011;7:257-62

24. Sperling RA, Aisen PS, Beckett LA, et al. Toward defining the preclinical stages of Alzheimer's disease: recommendations from the
National Institute on Aging-Alzheimer's Association workgroups on diagnostic guidelines for Alzheimer's disease. Alzheimers Dement 2011;7:280-92

25. Roberts RO, Geda YE, Knopman DS, et al. The Mayo Clinic Study of Aging: design and sampling, participation, baseline measures and sample characteristics. Neuroepidemiology 2008;30:58-69

26. Jack CR Jr, Knopman DS, Weigand SD, et al. An operational approach to National Institute on Aging-Alzheimer's Association criteria for preclinical Alzheimer disease. Ann Neurol 2012;71:765-75

27. Knopman DS, Jack CR Jr, Wiste HJ, et al. Short-term clinical outcomes for stages of NIA-AA preclinical Alzheimer disease. Neurology 2012;78:1576-82

28. Knopman DS, Jack CR, Jr., Wiste HJ, et al. Brain injury biomarkers are not dependent on beta-amyloid in normal elderly. Ann Neurol 2012 Nov 23. [Epub ahead of print]

29. Petersen RC, Aisen P, Boeve BF, et al. Criteria for mild cognitive impairment due to Alzheimer's disease in the community. Ann Neurol 2013 May 20. [Epub ahead of print]

30. Mosconi L, Andrews RD, Matthews DC. Comparing brain amyloid deposition, glucose metabolism, and atrophy in mild cognitive impairment with and without a family history of dementia. J Alzheimers Dis 2013;35:509-24

31. Vemuri P, Lesnick TG, Przybelski SA, et al. Effect of lifestyle activities on Alzheimer disease biomarkers and cognition. Ann Neurol 2012;72:730-38

32. Kemppainen NM, Aalto S, Karrasch M, et al. Cognitive reserve hypothesis: Pittsburgh compound B and fluorodeoxyglucose positron emission tomography in relation to education in mild Alzheimer's disease. Ann Neurol 2008;63:112-18

33. Mathis CA, Wang Y, Holt DP, et al. Synthesis and evaluation of 11C-labeled 6-substituted 2-arylbenzothiazoles as amyloid imaging agents. J Med Chem 2003;46:2740-54

34. Manook A, Yousefi BH, Willuweit A, et al. Small-animal PET imaging of amyloid-beta plaques with $[11 \mathrm{C}] \mathrm{PiB}$ and its multi-modal validation in an APP/PS1 mouse model of Alzheimer's disease. PLoS One 2012;7:e31310

35. Ikonomovic MD, Klunk WE, Abrahamson EE, et al. Post-mortem correlates of in vivo PiB-PET amyloid imaging in a typical case of Alzheimer's disease. Brain 2008;131:1630-45

36. Choi SR, Schneider JA, Bennett DA, et al. Correlation of amyloid PET ligand florbetapir F 18 binding with Abeta aggregation and neuritic plaque deposition in postmortem brain tissue. Alzheimer Dis Assoc Disord 2012;26:8-16

37. Lin KJ, Hsu WC, Hsiao IT, et al. Whole-body biodistribution and brain PET imaging with $[18 \mathrm{~F}] \mathrm{AV}-45$, a novel amyloid imaging agent-a pilot study. Nucl Med Biol 2010;37:497-508

38. Wong DF, Rosenberg PB, Zhou Y, et al. In vivo imaging of amyloid deposition in Alzheimer disease using the radioligand 18F-AV-45 (florbetapir [corrected] F 18). J Nucl Med 2010;51:913-20

39. Poisnel G, Dhilly M, Moustie O, et al. PET imaging with [18F]AV-45 in an APP/PS1-21 murine model of amyloid plaque deposition. Neurobiol Aging 2012;33:2561-71

40. Cselényi Z, Jonhagen ME, Forsberg A, et al. Clinical validation of 18F-AZD4694, an amyloid-beta-specific PET radioligand. $J \mathrm{Nucl}$ Med 2012;53:415-24

41. Rowe CC, Pejoska S, Mulligan RS, et al. Head-to-head comparison of 11C-PiB and 18F-AZD4694 (NAV4694) for beta-amyloid imaging in aging and dementia. $J$ Nucl Med 2013;54:880-86

42. Villemagne VL, Mulligan RS, Pejoska S, et al. Comparison of 11C$\mathrm{PiB}$ and 18F-florbetaben for Abeta imaging in ageing and Alzheimer's disease. Eur J Nucl Med Mol Imaging 2012;39:983-89

43. Wolk DA, Zhang Z, Boudhar S, et al. Amyloid imaging in Alzheimer's disease: comparison of florbetapir and Pittsburgh compound-B positron emission tomography. J Neurol Neurosurg Psychiatry 2012;83:923-26

44. Becker GA, Ichise M, Barthel H, et al. PET quantification of $18 \mathrm{~F}-$ florbetaben binding to beta-amyloid deposits in human brains. J Nucl Med 2013;54:723-31 
45. Landau SM, Breault C, Joshi AD, et al. Amyloid-beta imaging with Pittsburgh compound $\mathrm{B}$ and florbetapir: comparing radiotracers and quantification methods. J Nucl Med 2013;54:70-77

46. Burack MA, Hartlein J, Flores HP, et al. In vivo amyloid imaging in autopsy-confirmed Parkinson disease with dementia. Neurology 2010;74:77-84

47. Kantarci K, Yang C, Schneider JA, et al. Antemortem amyloid imaging and beta-amyloid pathology in a case with dementia with Lewy bodies. Neurobiol Aging 2012;33:878-85

48. Fodero-Tavoletti MT, Smith DP, McLean CA, et al. In vitro characterization of Pittsburgh compound-B binding to Lewy bodies. J Neurosci 2007;27:10365-71

49. Ye L, Velasco A, Fraser $G$, et al. In vitro high affinity alpha-synuclein binding sites for the amyloid imaging agent PIB are not matched by binding to Lewy bodies in postmortem human brain. J Neurochem 2008;105:1428-37

50. Lockhart A, Lamb JR, Osredkar T, et al. PIB is a non-specific imaging marker of amyloid-beta (Abeta) peptide-related cerebral amyloidosis. Brain 2007;130:2607-15

51. Ikonomovic MD, Abrahamson EE, Price JC, et al. Early AD pathology in a [C-11] PiB-negative case: a PiB-amyloid imaging, biochemical, and immunohistochemical study. Acta Neuropathol 2012;123:433-47

52. Clark CM, Schneider JA, Bedell BJ, et al. Use of florbetapir-PET for imaging beta-amyloid pathology. JAMA 2011;305:275-83

53. Sojkova J, Driscoll I, Iacono D, et al. In vivo fibrillar beta-amyloid detected using $[11 \mathrm{C}] \mathrm{PiB}$ positron emission tomography and neuropathologic assessment in older adults. Arch Neurol 2011;68: 232-40

54. Kantarci K, Lowe VJ, Boeve BF, et al. Multimodality imaging characteristics of dementia with Lewy bodies. Neurobiol Aging 2012; 33:2091-105

55. Villemagne VL, Ong K, Mulligan RS, et al. Amyloid imaging with (18)F-florbetaben in Alzheimer disease and other dementias. J Nucl Med 2011;52:1210-17

56. Rabinovici GD, Rosen HJ, Alkalay A, et al. Amyloid vs FDG-PET in the differential diagnosis of AD and FTLD. Neurology 2011;77:2034-42

57. Schneider JA, Arvanitakis Z, Bang W, et al. Mixed brain pathologies account for most dementia cases in community-dwelling older persons. Neurology 2007;69:2197-204

58. Sonnen JA, Santa Cruz K, Hemmy LS, et al. Ecology of the aging human brain. Arch Neurol 2011;68:1049-56

59. Edison P, Rowe CC, Rinne JO, et al. Amyloid load in Parkinson's disease dementia and Lewy body dementia measured with [11C]PIB positron emission tomography. J Neurol Neurosurg Psychiatry 2008;79:1331-38

60. Foster ER, Campbell MC, Burack MA, et al. Amyloid imaging of Lewy body-associated disorders. Mov Disord 2010;25:2516-23

61. Gomperts SN, Rentz DM, Moran E, et al. Imaging amyloid deposition in Lewy body diseases. Neurology 2008;71:903-10

62. Maetzler W, Liepelt I, Reimold M, et al. Cortical PIB binding in Lewy body disease is associated with Alzheimer-like characteristics. Neurobiol Dis 2009;34:107-12

63. Kantarci K, Ferman TJ, Boeve BF, et al. Focal atrophy on MRI and neuropathologic classification of dementia with Lewy bodies. Neurology 2012;79:553-60

64. O’Brien JT, Colloby S, Fenwick J, et al. Dopamine transporter loss visualized with FP-CIT SPECT in the differential diagnosis of dementia with Lewy bodies. Arch Neurol 2004;61:919-25

65. Villemagne VL, Okamura N, Pejoska S, et al. Differential diagnosis in Alzheimer's disease and dementia with Lewy bodies via VMAT2 and amyloid imaging. Neurodegener Dis 2012;10:161-65

66. Camus V, Payoux P, Barre L, et al. Using PET with 18F-AV-45 (florbetapir) to quantify brain amyloid load in a clinical environment. Eur J Nucl Med Mol Imaging 2012;39:621-31

67. Frederiksen KS, Hasselbalch SG, Hejl AM, et al. Added diagnostic value of (11)C-PiB-PET in memory clinic patients with uncertain diagnosis. Dement Geriatr Cogn Dis Extra 2012;2:610-21

68. Ossenkoppele R, Prins ND, Pijnenburg YA, et al. Impact of molecu- lar imaging on the diagnostic process in a memory clinic. Alzheimers Dement 2013;9:414-21

69. Frisoni GB, Bocchetta M, Chetelat G, et al. Imaging markers for Alzheimer disease: which vs how. Neurology 2013;81:487-500

70. Mitka M. PET imaging for Alzheimer disease: are its benefits worth the cost? JAMA 2013;309:1099-100

71. Jack CR Jr, Knopman DS, Jagust WJ, et al. Hypothetical model of dynamic biomarkers of the Alzheimer's pathological cascade. Lancet Neurol 2010;9:119-28

72. Jack CR Jr, Knopman DS, Jagust WJ, et al. Tracking pathophysiological processes in Alzheimer's disease: an updated hypothetical model of dynamic biomarkers. Lancet Neurol 2013;12:207-16

73. Jack CR Jr, Wiste HJ, Lesnick TG, et al. Brain beta-amyloid load approaches a plateau. Neurology 2013;80:890-96

74. Villemagne VL, Burnham S, Bourgeat P, et al. Amyloid beta deposition, neurodegeneration, and cognitive decline in sporadic Alzheimer's disease: a prospective cohort study. Lancet Neurol 2013;12:357-67

75. Kadir A, Almkvist O, Forsberg A, et al. Dynamic changes in PET amyloid and FDG imaging at different stages of Alzheimer's disease. Neurobiol Aging 2012;33:198.e1-14

76. Koivunen J, Scheinin N, Virta JR, et al. Amyloid PET imaging in patients with mild cognitive impairment: a 2-year follow-up study. Neurology 2011;76:1085-90

77. Ossenkoppele R, Tolboom N, Foster-Dingley JC, et al. Longitudinal imaging of Alzheimer pathology using [11C]PIB, [18F]FDDNP and [18F]FDG PET. Eur J Nucl Med Mol Imaging 2012;39:990-1000

78. Sojkova J, Zhou Y, An Y, et al. Longitudinal patterns of beta-amyloid deposition in nondemented older adults. Arch Neurol 2011;68: 644-49

79. Villemagne VL, Pike KE, Chetelat G, et al. Longitudinal assessment of Abeta and cognition in aging and Alzheimer disease. Ann Neurol 2011;69:181-92

80. Villain N, Chetelat G, Grassiot B, et al. Regional dynamics of amyloid-beta deposition in healthy elderly, mild cognitive impairment and Alzheimer's disease: a voxelwise PiB-PET longitudinal study. Brain 2012;135:2126-39

81. Jack CR Jr, Lowe VJ, Weigand SD, et al. Serial PIB and MRI in normal, mild cognitive impairment and Alzheimer's disease: implications for sequence of pathological events in Alzheimer's disease. Brain 2009; 132:1355-65

82. Bateman RJ, Xiong C, Benzinger TL, et al. Clinical and biomarker changes in dominantly inherited Alzheimer's disease. N Engl J Med 2012;367:795-804

83. Fleisher AS, Chen K, Quiroz YT, et al. Florbetapir PET analysis of amyloid-beta deposition in the presenilin 1 E280A autosomal dominant Alzheimer's disease kindred: a cross-sectional study. Lancet Neurol 2012;11:1057-65

84. Sperling RA, Jack CR Jr, Aisen PS. Testing the right target and right drug at the right stage. Sci Transl Med 2011;3:111cm33

85. Barthel H, Luthardt J, Becker G, et al. Individualized quantification of brain beta-amyloid burden: results of a proof of mechanism phase 0 florbetaben PET trial in patients with Alzheimer's disease and healthy controls. Eur J Nucl Med Mol Imaging 2011;38:1702-14

86. Rinne JO, Brooks DJ, Rossor MN, et al. 11C-PiB PET assessment of change in fibrillar amyloid-beta load in patients with Alzheimer's disease treated with bapineuzumab: a phase 2, double-blind, placebo-controlled, ascending-dose study. Lancet Neurol 2010;9:363-72

87. Small GW, Siddarth P, Kepe V, et al. Prediction of cognitive decline by positron emission tomography of brain amyloid and tau. Arch Neurol 2012;69:215-22

88. Small GW, Kepe V, Ercoli LM, et al. PET of brain amyloid and tau in mild cognitive impairment. N Engl J Med 2006;355:2652-63

89. Okamura N, Furumoto S, Harada R, et al. Novel 18F-labeled arylquinoline derivatives for noninvasive imaging of tau pathology in Alzheimer eisease. J Nucl Med 2013;54:1420-27

90. Petersen RC. Mild cognitive impairment as a diagnostic entity. J Intern Med 2004;256:183-94 